\title{
The Relationship between Overweight and Overactive Bladder Symptoms
}

\author{
Magdaléna Hagovska ${ }^{a}$ Ján Švihrab Alena Bukovác ${ }^{\text {Agata Horbacz }}{ }^{c}$ \\ Dana Dračkovác Ján Lupták ${ }^{b}$ Ján Švihra Jr. ${ }^{b}$ \\ aDepartment of Physiatry, Balneology, and Medical Rehabilitation, Faculty of Medicine, \\ PJ Safarik University, Kosice, Slovak Republic; ${ }^{\text {b}}$ Department of Urology, Jessenius Faculty \\ of Medicine, Martin, Comenius University Bratislava, University Hospital Martin, \\ Martin, Slovak Republic; ' Institute of Physical Education and Sport, PJ Safarik University, \\ Kosice, Slovak Republic
}

Keywords
Overweight $\cdot$ Body fat percentage $\cdot$ Overactive bladder

\begin{abstract}
Background: Several authors have investigated the relationship between obesity - assessed only by body mass index (BMI) - and overactive bladder (OAB) symptoms. Objectives: The objective of this study was to determine the relationship between body fat percentage (BFP) and the severity of OAB symptoms with an impact on quality of life. Design: Cross-sectional study. The sample consisted of 206 overweight women; they were university students (BMI = $25.8 \pm 3.0$ ) with an average age of $30.6 \pm 2.4$ years. Body composition analysis was used, including assessment of BFP, visceral fat area $\left(\mathrm{cm}^{2} /\right.$ level), and other parameters. OAB symptoms were evaluated with an $O A B$ questionnaire $(O A B-q)$, voiding diary, and quality of life scale (IQoL). Results: Ninety women had a BFP $>32 \%$ and 116 had a BFP $<32 \%$. The voiding diary and $O A B-q$ confirmed significant differences in 24-h daytime and nighttime frequency of voiding and average urine volume during the day. The OAB-q symptom score was lower in the group with BFP $<32 \%$. I-QoL recorded significantly worse parameters in the group with BFP $>32 \%(p<0.01)$. The Patient Perception of Intensity of Urgency Scale significantly correlated with BFP $(r=0.466, p<0.001)$. Women with a BFP above $32 \%$ had a 1.95 times greater chance of developing $\mathrm{OAB}$ (odds ratio $=1.95,95 \% \mathrm{Cl}=1.09-3.52, p<0.02$ ). Conclusion: Young women with a BFP $>32 \%$ were $95 \%$ more likely to have OAB than other young women with a BPF $<32 \%$.


Hagovska et al.: Overweight and Overactive Bladder

\section{Introduction}

Overweight is generally due to excess body fat. The body mass index (BMI) values for overweight are between 25 and 29.9 [1]. However, overweight may also be due to extra muscle, bone, or water. Being overweight may lead to obesity. It brings with it not only an increased risk of cardiovascular disease and metabolic syndrome, but also urological dysfunctions, including overactive bladder (OAB) $[2,3]$.

The methods for measurement of body fat are computed tomography and dual-energy X-ray absorptiometry and they are considered the gold standards for the evaluation of body fat distribution, but they are costly and therefore too complicated for use in population studies [4]. A frequently used method is bioelectrical impedance analysis. This is a method that is often used in clinical practice to evaluate body composition, including body fat percentage (BFP), and is low in cost and strongly correlates with dual-energy X-ray absorptiometry and computed tomography or magnetic resonance imaging [5].

BMI is only an informative indicator, as it does not distinguish between body fat and skeletal muscle mass (SMM). BMI can be increased even if the body has more muscle mass. Therefore, it is important to measure the BFP of the overall weight for the diagnosis of overweight and obesity. The American Exercise Committee describes overweight as 32-39\% body fat in women and 23-29\% body fat in men [2]. Abdominal obesity is caused by an accumulation of body fat and visceral fat in the abdominal cavity. It increases intra-abdominal and intravesical pressure, which may lead to the development of stress urinary incontinence (SUI), urgency urinary incontinence (UUI), and OAB [6].

The International Continence Society and the International Urogynecological Association define $\mathrm{OAB}$ as urinary urgency, usually accompanied by frequency and nocturia, with or without UUI, and with the absence of urinary tract infection or other obvious pathology [7-9]. According to epidemiological studies, the prevalence of OAB was from 5 to $10 \%$ [10]. In young women aged 18-35 years, the prevalence of overweight was 16\% [11].

Several authors have investigated the relationship between obesity, assessed only by BMI, and OAB symptoms. $[12,13]$. However, few studies have examined the relationship between BFP in overweight young women and OAB symptoms, with an impact on life quality [14]. The aim of this study was to determine the relationship between BFP and the severity of OAB symptoms by assessing the impact on quality of life in a group of young women with overweight.

\section{Materials and Methods}

This cross-sectional study was approved by the ethics committee of the University Hospital in Martin, Slovakia, IRB approval number 255/2018. The study was conducted from March 2018 through September 2018. All women provided informed consent according to the Declaration of Helsinki.

The research sample consisted of female university students randomly selected from two universities. The number of participants was determined according to the prevalence of overweight, using the following formula: $n=\mathrm{Z}^{2} \mathrm{P}(1-\mathrm{P}) / \mathrm{d}^{2}$, where $n=$ sample size, $\mathrm{Z}=1.96(95 \%$ confidence level), $\mathrm{P}=$ the expected prevalence of overweight $(\mathrm{P}=0.16)$, and $\mathrm{d}=0.05$ (confidence interval $=10 \%)[12,15]$. The minimum number of participants was set at 195 individuals.

A total of 7,943 participants completed a screening questionnaire which collected demographic data. Calculation of the BMI was done according to the formula: $\mathrm{BMI}=\mathrm{m} / \mathrm{h}^{2}$, where $\mathrm{m}=$ body weight in $\mathrm{kg}$ and $\mathrm{h}=$ body height in $\mathrm{m}$. All overweight women (BMI 25-29.9) were

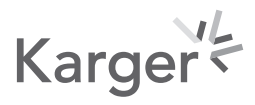




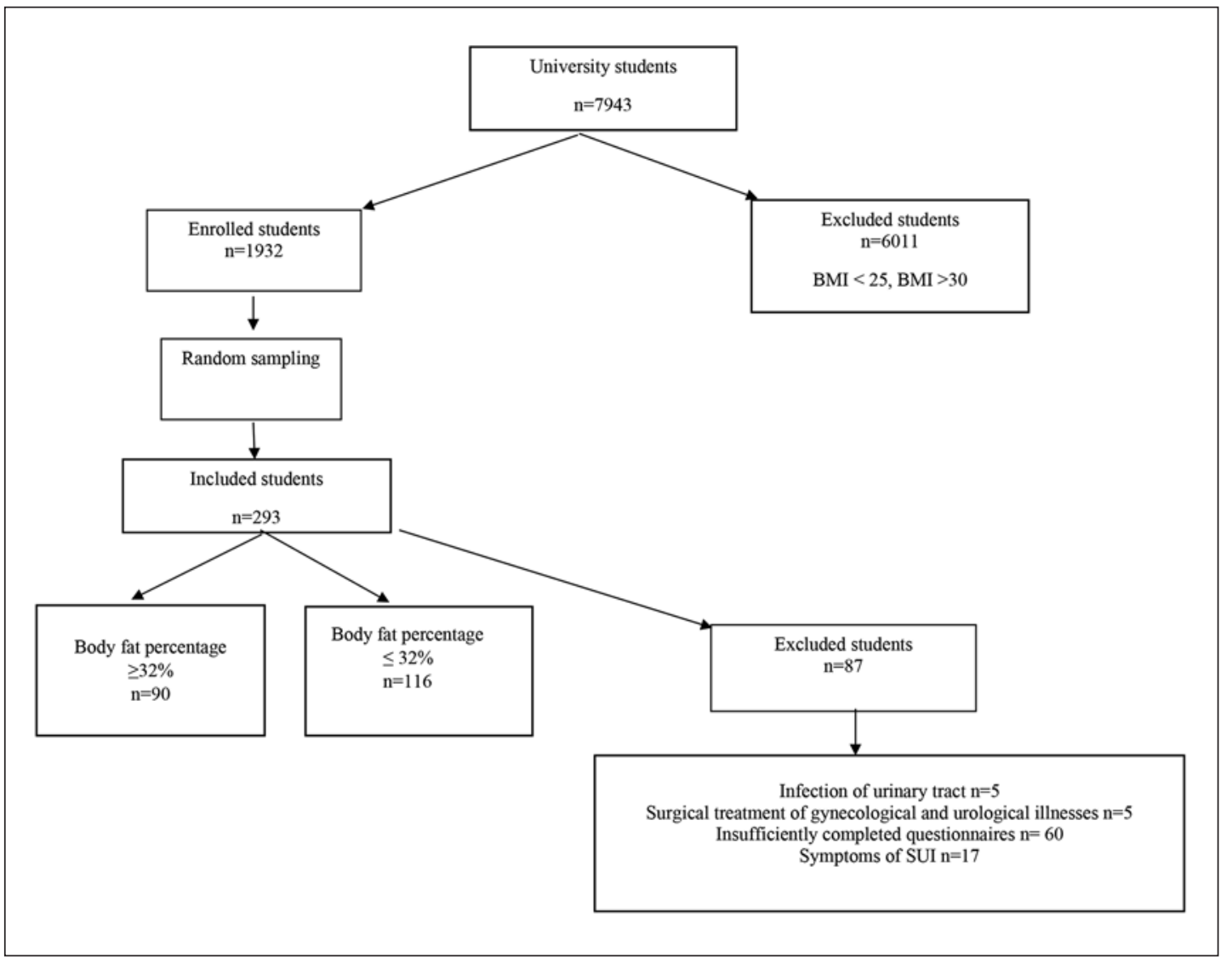

Fig. 1. Enrollment flow diagram.

enrolled, with a total of 1,932 women. Of the 1,932 women, 293 women were randomly selected to participate because we anticipated a loss of at least $25 \%$. An independent person who did not participate in the study performed random sampling using Microsoft Office Excel 2010. Data collection was anonymous. After completing the questionnaires, 87 women were excluded, as described in Figure 1.

According to the inclusion criteria, all participants were nulliparous women aged 18-35 years and overweight with BMI 25-29.9. Patients were excluded if they had genuine SUI, a history of surgical treatment of gynecological or urological diseases, infection of the urinary tract, neurological and/or oncological urinary tract disease, or incomplete questionnaires.

Body composition analysis was performed using a 230 BioSpace body composition analyzer. Measurements included BFP, visceral fat area (VFA) $\left(\mathrm{cm}^{2} /\right.$ level), SMM (kg), body fat mass (BFM) $(\mathrm{kg})$, and the waist circumference $(\mathrm{cm})$ to hip circumference $(\mathrm{cm})$ ratio (WHR) $[16,17]$.

The International Continence Society and the International Urogynecological Association define $\mathrm{OAB}$ as urinary urgency, usually accompanied by frequency and nocturia, with or without UUI, in the absence of urinary tract infection or other obvious pathology [7].

Participants used a voiding diary that evaluated voided volume, number of voidings per $24 \mathrm{~h}(\mathrm{~mL})$, voided volume during the day $(\mathrm{mL})$, daytime frequency, voided volume during the night (mL), and nocturia. Data for 3 days and average values were calculated [7].

The OAB questionnaire (OAB-q) was used to determine the symptoms of UUI. Six questions assessed symptom scores that ranged from 0 (no symptoms) to 100 (the most symptoms). 
Hagovska et al.: Overweight and Overactive Bladder

Thirteen questions assessed quality of life, with scores ranging from 0 (the worst) to 100 (the best). Cronbach's alpha for the OAB-q is 0.90 [18-20].

The Patient Perception of Intensity of Urgency Scale (PPIUS) was used to determine the severity of symptoms of UUI, where $0=$ "No urgency. I felt no need to empty my bladder, but did so for other reasons.", 1 = "Mild urgency. I could postpone voiding as long as necessary, without fear of wetting myself.", 2 = "Moderate urgency. I could postpone voiding for a short while, without fear of wetting myself.", 3 = "Severe urgency. I could not postpone voiding, but had to rush to the toilet in order not to wet myself.", and $4=$ "Urge incontinence. I leaked before arriving to the toilet." The scale has an intra-class correlation coefficient of 0.95 and a Spearman's correlation of 0.89 [21, 22].

The Urinary Incontinence Quality of Life scale (I-QoL) consists of three subscales: (1) avoidance score and limiting behavior score, (2) psychosocial impact score, and (3) social embarrassment score. The I-QoL has 22 questions, with a total score ranging from 0 (worst life quality) to 100 (best life quality). The Cronbach's alpha reliability of the I-QoL is $0.91-0.96$ $[23,24]$.

\section{Statistical Processing}

Analytical and descriptive statistics were used. The data were presented as mean values and standard deviations. The data had a normal distribution, and $p$ values were obtained using a $t$ test. The significance level was set at $p<0.05$. The relationships between the variables were evaluated using the Spearman's correlation coefficient, $r$. Logistic regression analysis was used to determine the risk estimate (odds ratio) with a 95\% confidence interval. The receiver operating characteristics and area under the curve (AUC) were calculated for the prediction of $\mathrm{OAB}$ with the risk factor of being overweight. The calculations were performed using IBM SPSS, version 22.0 (Armonk, NY, USA).

\section{Results}

After evaluating the completed questionnaires from 206 women with a mean age of 30.6 \pm 2.04 years, average BMI of $25.8 \pm 3.0$, confirming that they were overweight, the group consisted of 90 women with a BFP higher than $32 \%$ and 116 women with a BFP less than $32 \%$.

No significant differences in BMI between these two groups were found. The prevalence of $\mathrm{OAB}$ in the group with $\mathrm{BFP}>32 \%$ was $57.7 \%$, and in the group with $\mathrm{BFP}<32 \%$, it was $12.2 \%$.

$\mathrm{OAB}-\mathrm{q}$ and the voiding diary confirmed significant differences in 24-h urination, daytime and nighttime urination frequencies, and average urine volume during the day, as well as the OAB-q symptom score, with significantly higher values in the group with a BFP $>32 \%$ $(p<0.01)$. The PPIUS confirmed significant differences between the groups, with significantly higher values in the group with a BFP $>32 \%(p<0.001)$. I-QoL recorded a significantly worse parameter in the group with a BFP $>32 \%$ for the overall score and the scores evaluating psychosocial impact and social embarrassment $(p<0.01)$. Results are shown in Table 1.

Significant differences were found in the BFM, VFA, and WHR, with significantly higher values in the group with a BFP $>32 \%(p<0.01)$. The results are shown in Table 2 .

We correlated body composition parameters and OAB parameters. Significant correlations were observed between the BFP and the voiding diary parameters (number of urinations per $24 \mathrm{~h}$, number of urinations over daytime and nighttime, night urine volume, mean urine volume per day, and OAB symptoms score). Significant correlations were observed

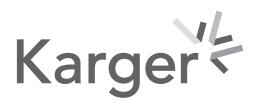




\begin{tabular}{|c|c|}
\hline \multicolumn{2}{|l|}{ Obes Facts 2020;13:297-306 } \\
\hline DOI: 10.1159/000506486 & $\begin{array}{l}\text { (c) } 2020 \text { The Author(s). Published by S. Karger AG, Basel } \\
\text { www.karger.com/ofa }\end{array}$ \\
\hline
\end{tabular}

Table 1. Statistical comparison of OAB-q, voiding diary, and I-QoL parameters according to body fat percentage

\begin{tabular}{|c|c|c|c|}
\hline Parameter & $\begin{array}{l}\text { Body fat percentage } \\
>32 \%(n=90)\end{array}$ & $\begin{array}{l}\text { Body fat percentage } \\
<32 \%(n=116)\end{array}$ & $\begin{array}{l}p \\
(t \text { test })\end{array}$ \\
\hline Age, years & $29.19 \pm 2.34$ & $27.58 \pm 1.72$ & 0.051 \\
\hline Body mass index & $26.79 \pm 3.0$ & $25.3 \pm 2.8$ & 0.61 \\
\hline Voided volume during $24 \mathrm{~h}, \mathrm{~mL}$ & $1,331.09 \pm 534.5$ & $1,292.63 \pm 463.6$ & 0.58 \\
\hline Number of voidings per $24 \mathrm{~h}$ & $8.08 \pm 2.72$ & $6.77 \pm 1.83$ & $<0.001$ \\
\hline Voided volume during day, $\mathrm{mL}$ & $1,173.02 \pm 538.42$ & $1,189.89 \pm 486.74$ & 0.81 \\
\hline Daytime frequency & $6.64 \pm 2.00$ & $5.83 \pm 1.20$ & $<0.001$ \\
\hline Voided volume during night, mL & $158.07 \pm 132.06$ & $102.74 \pm 129.96$ & $<0.05$ \\
\hline Nighttime frequency (nocturia) & $1.43 \pm 1.08$ & $0.94 \pm 0.98$ & $<0.001$ \\
\hline Mean voided volume per $24 \mathrm{~h}, \mathrm{~mL}$ & $170.16 \pm 68.60$ & $183.72 \pm 73.58$ & 0.17 \\
\hline Mean voided volume during day, $\mathrm{mL}$ & $181.84 \pm 82.53$ & $206.43 \pm 76.8$ & $<0.05$ \\
\hline Mean voided volume during night, mL & $114.13 \pm 42.7$ & $115.81 \pm 62.11$ & 0.86 \\
\hline PPIUS - Patient Perception of Intensity of Urgency Scale & $1.50 \pm 0.83$ & $0.31 \pm 0.46$ & $<0.001$ \\
\hline SS - symptom score OAB-q & $11.73 \pm 10.16$ & $8.79 \pm 8.47$ & $<0.05$ \\
\hline HR - life quality OAB-q & $93.57 \pm 7.50$ & $94.88 \pm 6.49$ & 0.18 \\
\hline Total score of I-QoL & $96.28 \pm 5.75$ & $97.90 \pm 3.36$ & $<0.01$ \\
\hline Avoidance and limiting behavior score & $95.06 \pm 7.13$ & $96.12 \pm 6.81$ & 0.28 \\
\hline Psychosocial impact score & $97.09 \pm 6.06$ & $99.18 \pm 1.90$ & $<0.001$ \\
\hline Social embarrassment score & $96.77 \pm 6.50$ & $98.44 \pm 3.57$ & $<0.05$ \\
\hline
\end{tabular}

Data are presented as mean \pm standard deviation. $p$ values were obtained by non-paired $t$ test.

Table 2. Statistical comparison of body composition parameters according to body fat percentage

\begin{tabular}{lccc}
\hline Parameter & $\begin{array}{l}\text { Body fat percentage } \\
>32 \%(n=90)\end{array}$ & $\begin{array}{l}\text { Body fat percentage } \\
<32 \%(n=116)\end{array}$ & $\begin{array}{l}p \\
(t \text { test })\end{array}$ \\
\hline Body composition analysis & & & \\
$\quad$ Skeletal muscle mass, kg & $25.21 \pm 3.81$ & $24.81 \pm 3.29$ & $<.42$ \\
$\quad$ Body fat mass, kg & $26.78 \pm 6.80$ & $18.00 \pm 6.61$ & $<0.001$ \\
Body fat percentage, $\%$ & $37.38 \pm 4.76$ & $26.06 \pm 4.24$ & $<0.001$ \\
Visceral fat area, $\mathrm{cm}^{2} /$ level & $108.54 \pm 27.71$ & $73.00 \pm 24.04$ & $<0.001$ \\
WHR circumference index, cm/hips, cm & $2.80 \pm 12.61$ & $0.86 \pm 0.54$ & $<0.01$ \\
Waist, cm & $92.04 \pm 9.49$ & $82.22 \pm 9.11$ & $<0.001$ \\
\hline
\end{tabular}

Data are presented as mean \pm standard deviation. $p$ values were obtained by non-paired $t$ test.

between the VFA and the voiding diary parameters (number of urinations per $24 \mathrm{~h}$, number of urinations over daytime and nighttime, and urine volume over $24 \mathrm{~h}$ ). PPIUS scores significantly correlated with BFP. A significant correlation was observed between the number of urinations per day and BFM, WHR index, and waist circumference. No significant correlation was observed between muscle mass and OAB parameters (Table 3 ).

The ROC curves express the prediction of OAB development according to the individual parameters of the body composition analysis. All AUC values achieved a positive prediction in the monitored parameters in the participating women (Fig. 2; Table 4). Mean VFA was most strongly associated with $\mathrm{OAB}$, as denoted by the significantly large AUC (0.70) (Table 4).

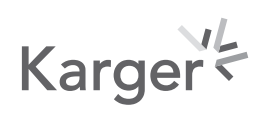




\begin{tabular}{l}
\hline Obes Facts 2020;13:297-306 \\
\hline DOI: 10.1159/000506486 \\
$\begin{array}{l}\text { (c) 2020 The Author(s). Published by S. Karger AG, Basel } \\
\text { www.karger.com/ofa }\end{array}$ \\
\hline
\end{tabular}

Hagovska et al.: Overweight and Overactive Bladder

Table 3. Spearman correlation coefficient $r$ of body composition parameters and $\mathrm{OAB}$

\begin{tabular}{|c|c|c|c|c|c|c|c|}
\hline Body composition analysis & BMI & $\begin{array}{l}\text { Skeletal } \\
\text { muscle } \\
\text { mass, kg }\end{array}$ & $\begin{array}{l}\text { Body fat } \\
\text { mass, kg }\end{array}$ & $\begin{array}{l}\text { Body fat } \\
\text { percentage, } \\
\%\end{array}$ & $\begin{array}{l}\text { Visceral } \\
\text { fat area, } \\
\mathrm{cm}^{2} / \text { level }\end{array}$ & $\begin{array}{l}\text { WHR } \\
\text { index, } \\
\mathrm{cm} / \mathrm{cm}\end{array}$ & $\begin{array}{l}\text { Waist, } \\
\mathrm{cm}\end{array}$ \\
\hline Voided volume during $24 \mathrm{~h}, \mathrm{~mL}$ & 0.070 & -0.049 & 0.120 & 0.032 & $0.188^{* *}$ & 0.121 & 0.125 \\
\hline Number of voidings per $24 \mathrm{~h}$ & 0.174 & -0.033 & 0.112 & $0.281^{* *}$ & $0.229 * *$ & 0.131 & 0.101 \\
\hline Voided volume during day, mL & 0.009 & -0.054 & 0.075 & -0.066 & 0.105 & 0.072 & 0.080 \\
\hline Daytime frequency & 0.177 & -0.018 & $0.196^{* *}$ & $0.266^{* *}$ & $0.307^{* *}$ & $0.215^{* *}$ & $0.199^{* *}$ \\
\hline Voided volume during night, $\mathrm{mL}$ & 0.140 & -0.069 & 0.016 & $0.228^{* *}$ & 0.119 & 0.032 & -0.011 \\
\hline Nighttime frequency (nocturia) & 0.167 & -0.033 & 0.051 & $0.262^{* *}$ & $0.155^{*}$ & 0.072 & 0.033 \\
\hline Mean voided volume per $24 \mathrm{~h}, \mathrm{~mL}$ & 0.008 & -0.056 & 0.089 & -0.068 & 0.091 & 0.094 & 0.101 \\
\hline Mean voided volume during day, mL & -0.049 & -0.039 & -0.006 & $-0.182^{* *}$ & -0.015 & -0.003 & 0.003 \\
\hline $\begin{array}{l}\text { Mean voided volume during night, } \mathrm{mL} \\
\text { PPIUS - Patient Perception of }\end{array}$ & -0.025 & -0.101 & -0.023 & -0.017 & -0.005 & -0.041 & -0.042 \\
\hline Intensity of Urgency Scale & $0.23^{* *}$ & 0.026 & $0.241^{* *}$ & $0.466^{* *}$ & $0.318^{* *}$ & $0.192^{* *}$ & $0.194^{* *}$ \\
\hline SS - symptom score OAB-q & 0.025 & -0.065 & 0.036 & $0.182^{* *}$ & 0.123 & 0.077 & 0.047 \\
\hline HR - quality of life OAB-q & 0.009 & 0.057 & 0.072 & -0.094 & -0.038 & -0.011 & 0.033 \\
\hline
\end{tabular}

${ }^{*} p \leq 0.05,{ }^{* *} p \leq 0.001$.

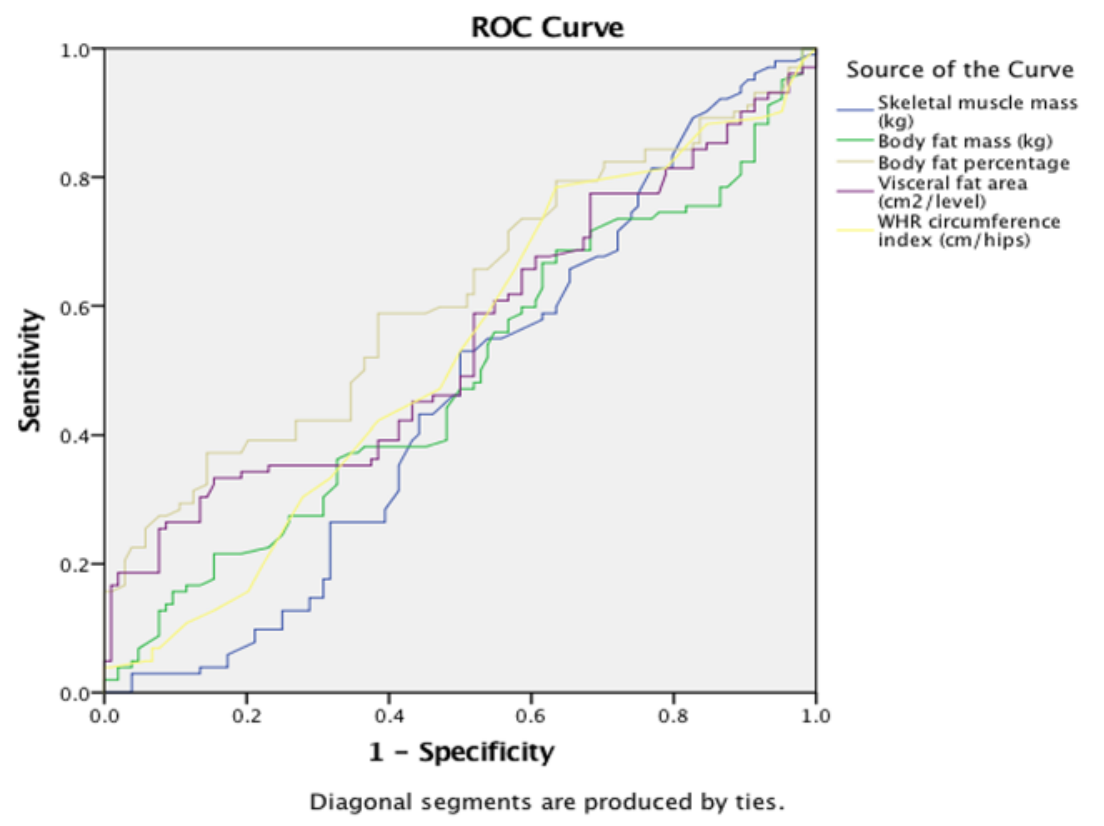

Fig. 2. Area under the curve - prediction of overactive bladder according to body composition.

\section{Discussion/Conclusion}

The aim of this study was to determine the relationship between BFP and the severity of $\mathrm{OAB}$ symptoms and the impact on life quality in a group of young women with overweight. No significant differences in BMI between these two groups were found. 
Table 4. Area under the curve prediction of the overactive bladder according to the body composition

\begin{tabular}{lll}
\hline Test result variable(s) & Area & $\begin{array}{l}\text { 95\% confidence interval } \\
\text { (lower-upper) }\end{array}$ \\
\hline Skeletal muscle mass (kg) & 0.44 & $0.38-0.54$ \\
Body fat mass $(\mathrm{kg})$ & 0.63 & $0.41-0.57$ \\
Body fat percentage (\%) & 0.53 & $0.53-0.69$ \\
Visceral fat area $\left(\mathrm{cm}^{2} /\right.$ level) & 0.70 & $0.47-0.72$ \\
WHR circumference index & & \\
$\quad 0.70$ & $0.44-0.70$ \\
$\quad(\mathrm{~cm}) /$ hips $(\mathrm{cm})$ & & \\
\hline
\end{tabular}

The prevalence of $\mathrm{OAB}$ in the group of women with $\mathrm{BFP}>32 \%$ was $57.7 \%$. The OAB-q and the voiding diary confirmed significant differences between the groups, with considerably worse values in the group with a BFP $>32 \%$. We found a relationship between increased BFP and worsened $\mathrm{OAB}$ symptoms, as evaluated by a voiding diary, the intensity of urgency scale (PPIUS), and the OAB-q. A BFP higher than $32 \%$ has an influence on OAB symptoms, with a negative impact on quality of life.

We evaluated the OAB prediction for body composition parameters. The ROC curves expressed the prediction of $\mathrm{OAB}$ according to individual body composition analysis parameters. All AUC values achieved a positive prediction for the monitored parameters in the female body. According to the obtained analysis, when the BFP is above $32 \%$, the probability of $\mathrm{OAB}$ occurrence is $70 \%$.

The precise mechanisms explaining the relationship between obesity, overweight, and $\mathrm{OAB}$ are not well understood. Some authors report that excess body weight increases intraabdominal pressure, which in turn increases bladder pressure and intravesical pressure, leading to excessive activity of the urinary bladder [25].

Ko et al. [26] examined the relationship between obesity and urinary incontinence, finding that overweight women have SUI and mixed urinary incontinence more frequently than women with normal weight. However, the women in their study were much older 53.8 years) than those in our study. Furthermore, they did not use a body composition analysis or a voiding diary, which were used in our research.

There is currently an ongoing discussion about the impact of overweight on OAB. Al-Shaiji and Radomski [27] studied 113 obese patients with an average age about 55 years and found that a BMI above 30 was related to an increased incidence of mixed incontinence and the use of inserts. However, urodynamic examination did not confirm a significant relationship with obesity and overweight evaluated by BMI and urodynamic parameters, besides urinary leakage. In our research, we found that the BFP most strongly correlated with the OAB parameters, followed by the VFA, and minimally correlated with BFM, the WHR index, and waist circumference. Muscle mass did not correlate with OAB.

Uzun and Zorba [28] found a correlation between metabolic syndrome and OAB in 313 obese and overweight women with an average age about 50 years. They evaluated obesity only by means of BMI, with an average of 27, and an average waist circumference of $31 \mathrm{~cm}$.

Zacche et al. [6] found a correlation between obesity and OAB in 260 overweight women and 272 obese women with an average age about 50 years. However, these authors only evaluated obesity and overweight by BMI. By contrast, we used several parameters of bioelectrical impedance analysis for the evaluation of overweight: SMM, BFM, BFP, VFA, and WHR index. The incidence of OAB in women with obesity, according to Zacche [6], is explained by a chronic increase in intraabdominal pressure. The authors recommended a reduction of weight, behavioral training, and patient education.

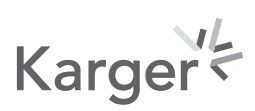


Brucker et al. [29] assessed whether overweight and obesity in 166 women, assessed with a mean BMI of 45 and with an average age about 35-40 years, was associated with urogynecological symptoms and reduced life quality. SUI and mixed urinary incontinence were found in half of the women, as well as frequent negative impacts on life quality. There was no positive correlation between obesity and urogynecological symptoms. In our study, we recorded a significant effect of OAB symptoms on the quality of life in the group with a BFP $>32 \%$.

\section{Strengths and Limitations}

A strength of our study is the use of an objective method for the assessment of body composition - bioelectrical impedance analysis. Many authors have used this for the assessment of obesity and overweight only, but we focused on the objective evaluation of overweight through BFP and other parameters of bioimpedance analysis. The abovementioned investigation is low in cost, fast, and painless. This study deals with the risk factor of being overweight and $\mathrm{OAB}$ symptoms and explains the relationship between them, with advice to prevent the worsening of $\mathrm{OAB}$ symptoms in the future.

A limitation of our study is the small number of inclusion criteria, e.g., other age categories. Average BMI was at the low end of the overweight range, meaning that we need larger generalizability of the population in the future; this could have affected our results. Moreover, it would be more appropriate to perform examinations by means of bioelectrical impedance analysis and $\mathrm{OAB}$ in women with normal weight and subsequently on obese women, and then analyze these factors.

We concluded, that no significant differences in BMI between these two groups were found. The OAB-q and voiding diary confirmed significant differences between the groups, with significantly worse values in the group with a BFP $>32 \%$. We found a relationship between an increased BFP and worsened OAB symptoms, as evaluated by a voiding diary, the PPIUS, and the OAB-q. According to the completed AUC analysis, when the BFP is above $32 \%$, the probability of $\mathrm{OAB}$ occurrence is $70 \%$. Overweight women should be informed of the risk of the occurrence of $\mathrm{OAB}$ and the causes of $\mathrm{OAB}$ development. In addition to adjusting dietary habits, appropriate and regular exercise activity should be advised.

\section{Statement of Ethics}

The protocol was approved by the ethics committee of the University Hospital in Martin, Slovakia. IRB approval number 255/2018. Prior to a patient's participation in the trial, the written informed consent form will be signed and personally dated by the patient.

\section{Disclosure Statement}

The authors declare that they have no competing interests.

\section{Funding Sources}

This work was supported by Ministry of Health of the Slovak Republic under the project registration number 2018/5-UKMT-1 and by Grant project No. 1/0825/17. 
Hagovska et al.: Overweight and Overactive Bladder

\section{Author Contributions}

M.H. and J.Š. conceived of the article ideas and design; M.H. drafted, revised, and edited the manuscript; A.B., A.H., and D.D. provided for data collection. All authors (M.H., J.Š., A.B., D.D., A.H., J.S. Jr., and J.L.) have read and approved the final version of the manuscript and agree with the order of the presentation of the authors.

\section{References}

1 Hunskaar S. A systematic review of overweight and obesity as risk factors and targets for clinical intervention for urinary incontinence in women. Neurourol Urodyn. 2008;27(8):749-57.

2 Jensen MD, Ryan DH, Apovian CM, Ard JD, Comuzzie AG, Donato KA, et al.; American College of Cardiology/ American Heart Association Task Force on Practice Guidelines; Obesity Society. 2013 AHA/ACC/TOS guideline for the management of overweight and obesity in adults. Circulation. 2014 Jun;129(25 Suppl 2):S102-38.

3 Media Centre W. Obesity and overweight. World Health Organization (WHO); 2018. http://www.who.int/ mediacentre/factsheets/fs311/en/

4 Rollins KE, Javanmard-Emamghissi H, Awwad A, Macdonald IA, Fearon KC, Lobo DN. Body composition measurement using computed tomography: does the phase of the scan matter? Nutrition. 2017 Sep;41:37-44.

5 Xu W, Chafi H, Guo B, Heymsfield SB, Murray KB, Zheng J, et al. Quantitative Comparison of 2 Dual-Energy X-ray Absorptiometry Systems in Assessing Body Composition and Bone Mineral Measurements. J Clin Densitom. 2016 Jul-Sep;19(3):298-304.

6 Zacche MM, Giarenis I, Thiagamoorthy G, Robinson D, Cardozo L. Is there an association between aspects of the metabolic syndrome and overactive bladder? A prospective cohort study in women with lower urinary tract symptoms. Eur J Obstet Gynecol Reprod Biol. 2017 Oct;217:1-5.

7 Haylen BT, de Ridder D, Freeman RM, Swift SE, Berghmans B, Lee J, et al. An International Urogynecological Association (IUGA)/International Continence Society (ICS) joint report on the terminology for female pelvic floor dysfunction. Int Urogynecol J Pelvic Floor Dysfunct. 2010 Jan;21(1):5-26.

8 Truzzi JC, Gomes CM, Bezerra CA, Plata IM, Campos J, Garrido GL, et al. Overactive bladder - 18 years - Part II. Int Braz J Urol. 2016 Mar-Apr;42(2):199-214.

9 Pomian A, Lisik W, Kosieradzki M, Barcz E. Obesity and Pelvic Floor Disorders: A Review of the Literature. Med Sci Monit. 2016 Jun;22:1880-6.

10 Tikkinen KA, Tammela TL, Rissanen AM, Valpas A, Huhtala H, Auvinen A. Is the prevalence of overactive bladder overestimated? A population-based study in Finland. PLoS One. 2007 Feb;2(2):e195.

11 Eapen RS, Radomski SB. Review of the epidemiology of overactive bladder. Res Rep Urol. 2016 Jun;8:71-6.

12 Hu L, Huang X, You C, Li J, Hong K, Li P, et al. Prevalence of overweight, obesity, abdominal obesity and obesityrelated risk factors in southern China. PLoS One. 2017 Sep;12(9):e0183934.

13 Khullar V, Sexton CC, Thompson CL, Milsom I, Bitoun CE, Coyne KS. The relationship between BMI and urinary incontinence subgroups: results from EpiLUTS. Neurourol Urodyn. 2014 Apr;33(4):392-9.

14 Dursun M, Otunctemur A, Ozbek E, Sahin S, Besiroglu H, Koklu I. Stress urinary incontinence and visceral adipose index: a new risk parameter. Int Urol Nephrol. 2014 Dec;46(12):2297-300.

15 Daniel Wayne W. Biostatistics: A Foundation for Analysis in the Health Sciences. 6th ed. New York: John Wiley \& Sons; 1995

16 Gallagher D, Heymsfield SB, Heo M, Jebb SA, Murgatroyd PR, Sakamoto Y. Healthy percentage body fat ranges: an approach for developing guidelines based on body mass index. Am J Clin Nutr. 2000 Sep;72(3):694-701.

17 Bosy-Westphal A, Later W, Hitze B, Sato T, Kossel E, Gluer CC, et al. Accuracy of bioelectrical impedance consumer devices for measurement of body composition in comparison to whole body magnetic resonance imaging and dual X-ray absorptiometry. Obes Facts. 2008;1(6):319-24.

18 Coyne KS, Matza LS, Thompson CL. The responsiveness of the Overactive Bladder Questionnaire (OAB-q). Qual Life Res. 2005 Apr;14(3):849-55.

19 Coyne K, Revicki D, Hunt T, Corey R, Stewart W, Bentkover J, et al. Psychometric validation of an overactive bladder symptom and health-related quality of life questionnaire: the OAB-q. Qual Life Res. 2002 Sep;11(6): 563-74.

20 Cardozo L, Staskin D, Currie B, Wiklund I, Globe D, Signori M, et al. Validation of a bladder symptom screening tool in women with incontinence due to overactive bladder. Int Urogynecol J Pelvic Floor Dysfunct. 2014 Dec; 25(12):1655-63.

21 Cardozo L, Hessdörfer E, Milani R, Arañó P, Dewilde L, Slack M, et al.; SUNRISE Study Group. Solifenacin in the treatment of urgency and other symptoms of overactive bladder: results from a randomized, double-blind, placebo-controlled, rising-dose trial. BJU Int. 2008 Nov;102(9):1120-7.

22 Notte SM, Marshall TS, Lee M, Hakimi Z, Odeyemi I, Chen WH, et al. Content validity and test-retest reliability of Patient Perception of Intensity of Urgency Scale (PPIUS) for overactive bladder. BMC Urol. 2012 Sep;12(1): 26. 
23 Patrick DL, Martin ML, Bushnell DM, Yalcin I, Wagner TH, Buesching DP. Quality of life of women with urinary incontinence: further development of the incontinence quality of life instrument (I-QOL). Urology. 1999 Jan; 53(1):71-6.

24 Bushnell DM, Martin ML, Summers KH, Svihra J, Lionis C, Patrick DL. Quality of life of women with urinary incontinence: cross-cultural performance of 15 language versions of the I-QOL. Qual Life Res. 2005 Oct;14(8): 1901-13.

25 Al-Shaiji TF, Radomski SB. Relationship between Body Mass Index and Overactive Bladder in Women and Correlations with Urodynamic Evaluation. Int Neurourol J. 2012 Sep;16(3):126-31.

26 Ko IG, Lim MH, Choi PB, Kim KH, Jee YS. Effect of Long-term Exercise on Voiding Functions in Obese Elderly Women. Int Neurourol J. 2013 Sep;17(3):130-8.

27 Al-Shaiji TF, Radomski SB. Relationship between Body Mass Index and Overactive Bladder in Women and Correlations with Urodynamic Evaluation. Int Neurourol J. 2012 Sep;16(3):126-31.

28 Uzun H, Zorba OU. Metabolic syndrome in female patients with overactive bladder. Urology. 2012 Jan;79(1): 72-5.

29 Brucker J, Wagner I, Rudofsky G, Rauch G, Sohn C, Brocker KA. In obesity even young women suffer from urogynecological symptoms. Arch Gynecol Obstet. 2017 Nov;296(5):947-56. 